Research Article

\title{
Metformin and Its Sulfenamide Prodrugs Inhibit Human Cholinesterase Activity
}

\author{
Magdalena Markowicz-Piasecka, ${ }^{1}$ Joanna Sikora, ${ }^{1}$ Lukasz Mateusiak, ${ }^{2}$ \\ Elżbieta Mikiciuk-Olasik, ${ }^{3}$ and Kristiina M. Huttunen ${ }^{4}$
}

${ }^{1}$ Laboratory of Bioanalysis, Department of Pharmaceutical Chemistry, Drug Analysis and Radiopharmacy, Medical University of
Lodz, ul. Muszyńskiego 1, 90-151 Lodz, Poland
${ }^{2}$ Students Research Group, Laboratory of Bioanalysis, Department of Pharmaceutical Chemistry, Drug Analysis and Radiopharmacy,
Medical University of Lodz, ul. Muszyńskiego 1, 90-151 Lodz, Poland
${ }^{3}$ Department of Pharmaceutical Chemistry, Drug Analysis and Radiopharmacy, Medical University of Lodz, ul. Muszyńskiego 1,
90-151 Lodz, Poland
${ }^{4}$ School of Pharmacy, Faculty of Health Sciences, University of Eastern Finland, Yliopistonranta 1C, POB 1627 70211 Kuopio, Finland

Correspondence should be addressed to Magdalena Markowicz-Piasecka; magdalena.markowicz@umed.lodz.pl

Received 11 March 2017; Revised 5 June 2017; Accepted 14 June 2017; Published 9 July 2017

Academic Editor: Eduardo L. G. Moreira

Copyright (c) 2017 Magdalena Markowicz-Piasecka et al. This is an open access article distributed under the Creative Commons Attribution License, which permits unrestricted use, distribution, and reproduction in any medium, provided the original work is properly cited.

\begin{abstract}
The results of epidemiological and pathophysiological studies suggest that type 2 diabetes mellitus (T2DM) may predispose to Alzheimer's disease (AD). The two conditions present similar glucose levels, insulin resistance, and biochemical etiologies such as inflammation and oxidative stress. The diabetic state also contributes to increased acetylcholinesterase (AChE) activity, which is one of the factors leading to neurodegeneration in $\mathrm{AD}$. The aim of this study was to assess in vitro the effects of metformin, phenformin, and metformin sulfenamide prodrugs on the activity of human AChE and butyrylcholinesterase (BuChE) and establish the type of inhibition. Metformin inhibited $50 \%$ of the AChE activity at micromolar concentrations $(2.35 \mu \mathrm{mol} / \mathrm{mL}$, mixed type of inhibition) and seemed to be selective towards AChE since it presented low anti-BuChE activity. The tested metformin prodrugs inhibited cholinesterases (ChE) at nanomolar range and thus were more active than metformin or phenformin. The cyclohexyl sulfenamide prodrug demonstrated the highest activity towards both $\mathrm{AChE}\left(\mathrm{IC}_{50}=890 \mathrm{nmol} / \mathrm{mL}\right.$, noncompetitive inhibition) and $\mathrm{BuChE}\left(\mathrm{IC}_{50}=28 \mathrm{nmol} / \mathrm{mL}\right.$, mixed type inhibition), while the octyl sulfenamide prodrug did not present anti-AChE activity, but exhibited mixed inhibition towards $\mathrm{BuChE}\left(\mathrm{IC}_{50}=184 \mathrm{nmol} / \mathrm{mL}\right)$. Therefore, these two bulkier prodrugs were concluded to be the most selective compounds for BuChE over AChE. In conclusion, it was demonstrated that biguanides present a novel class of inhibitors for $\mathrm{AChE}$ and $\mathrm{BuChE}$ and encourages further studies of these compounds for developing both selective and nonselective inhibitors of ChEs in the future.
\end{abstract}

\section{Introduction}

Type 2 diabetes mellitus (T2DM) is a complex, chronic, and progressive metabolic disease characterized by relative insulin deficiency, insulin resistance (primarily in fat, liver, and muscle cells), and high glucose levels in blood $[1,2]$. Importantly, the disease can lead to severe impairments in almost all vital organs, including the brain.

A review of recent papers and epidemiological data shows an increased risk of developing Alzheimer's disease
(AD), a common neurodegenerative disease characterized by progressive memory shortfall and neuronal loss, in people with T2DM [3-6]. The pathological characteristics of $\mathrm{AD}$ include extracellular amyloid plaques consisting of aggregated amyloid $\beta$ protein $(\mathrm{A} \beta)$, intracellular neurofibrillary tangles (NFTs) comprising hyperphosphorylated tau protein, and neuronal loss [7]. Both acetylcholinesterase (AChE) and decreased acetylcholine (Ach) levels may play a role in the occurrence of $\mathrm{AD}$, as it has been reported that abnormal $\mathrm{AChE}$ expression in the $\mathrm{AD}$ brain occurs in association with 
amyloid plaques and NFTs $[8,9]$. A $\beta$ peptides influence $\mathrm{AChE}$ levels, and as a consequence, $\mathrm{A} \beta$ may be responsible for the increased AChE protein levels around plaques. However, as García-Ayllón et al. have highlighted, the increase in AChE associated with NFTs has not yet been sufficiently explored [10].

Several competing hypotheses have been proposed in order to explain the cause of AD. The oldest, on which currently available anti-AD therapeutics are based, is the cholinergic hypothesis, which postulates that reduced synthesis of acetylcholine $(\mathrm{ACh})$ is a factor in $\mathrm{AD}$ development. As the inhibition of AChE causes an increase in the concentration of ACh in cholinergic synapses, new and potent AChE inhibitors may be helpful in the treatment of AD [11].

AChE is a key enzyme in the cholinergic nervous system, and its levels are consistently decreased in the brain during $\mathrm{AD}$ development [12]. It has been well documented that the distribution of AChE molecular forms is particularly affected in the AD brain, but the pathological significance of these changes with regard to $\mathrm{AChE}$ species remains unknown. Another important issue regarding $\mathrm{AChE}$ in $\mathrm{AD}$ is that not all molecular forms of AChE are equally affected. It has been found that the proportion of G4 (tetramer) forms in $\mathrm{AD}$ brains is particularly depleted whereas the minor G1 (monomers) species are mostly preserved or even slightly increased [10]. It has been speculated that AChE plays a role in phases of cell development, such as neuronal differentiation, regulation of cell growth, or cell adhesion, which occur independently of its catalytic activity; a more detailed description of the role of $\mathrm{AChE}$ in $\mathrm{AD}$ pathogenesis is given by García-Ayllón et al. [10]. However, further studies are needed to elucidate the additional, noncatalytic functions of $\mathrm{AChE}$, their association with different $\mathrm{AChE}$ variants, and their role in $\mathrm{AD}$.

The mechanisms through which T2DM may predispose a patient to $\mathrm{AD}$ are not fully understood but may involve several factors including glucose levels, biochemical etiologies such as inflammation, and oxidative stress [13-15]. Several authors have reported that the relationship between diabetes and cognitive impairment may be associated with lowered insulin levels and its resistance. For instance, it has been established that insulin promotes synapse formation, neuronal stem cell activation, general cell growth, and neuroprotection [16]. Therefore, the disruption of insulin levels, insulin signalling, or insulin resistance in the brain can lead to the dysfunction and degeneration of neurons [17]. In addition, postmortem studies have found reduced neocortical levels of insulin and binding to insulin receptors in the brains of $\mathrm{AD}$ patients [18]. Deficiencies or impairments in insulin signalling may also intensify neurodegeneration by promoting the phosphorylation of tau [19]. Furthermore, insulin resistance has also been shown to promote $\mathrm{A} \beta$ accumulation and the progression of neurodegeneration in $\mathrm{AD}$ [20].

Some authors have also indicated a correlation between butyrylcholinesterase (BuChE) and insulin sensitivity [21], which implies that $\mathrm{BuChE}$ could have a crucial role in diabetes associated with insulin resistance [22]. The connection between BuChE activity and lipid and lipoprotein levels, stroke, preeclampsia, systemic lupus erythematosus, and cardiovascular disease has also been studied [23]. Moreover, $\mathrm{BuChE}$ protein levels were found to be elevated in the case of $\mathrm{AD}$ patients $[24,25]$ and they were also found to attenuate amyloid fibril formation [26].

Metformin is the most frequently used drug for the treatment of T2DM and is characterized by multidirectional biological activity: apart from hypoglycaemic activity, it exerts beneficial effects on mortality rate in diabetic patients, improves serum lipid profile, positively influences the process of haemostasis, which is often abnormal in diabetic patients, and stimulates the expression of genes responsible for cellular antioxidant defense mechanisms [27].

Recently, several papers have examined the use of metformin in the treatment of neurodegenerative diseases such as AD [28], amnestic mild cognitive impairment [29], and Parkinson's disease [30]. Curiously, other papers confirm a link between chronic administration of metformin and accumulation of $\beta$-amyloid aggregates [31-33]. For instance, Chen et al. report that metformin significantly increased the levels of extracellular and intracellular $A \beta$ species, and that metformin magnified the total BACE1 ( $\beta$-amyloidconverting enzyme 1) enzymatic activity twofold [34]. In contrast, Hettich et al. [35] claim that metformin markedly decreased BACE1 protein expression and activity in vitro and in vivo, thereby reducing the amount of BACE1 cleavage products and the production of $A \beta$ [35]. However, even less is known regarding the effects of metformin on AChE activity. One in vivo study found that metformin at a dose of $100 \mathrm{mg} / \mathrm{kg}$ ameliorates scopolamine-induced memory impairments; however, no significant effect was observed on the scopolamine-induced increase in AChE activity [36].

Therefore, taking into consideration the multidirectional activity of metformin, the aim of the present study was to assess in vitro the effects of metformin, phenformin, and three selected sulfenamide metformin prodrugs (Figure 1) on the activity of human $\mathrm{AChE}$ and $\mathrm{BuChE}$ and to establish the type of inhibition. The findings will provide a greater insight into the more rational design of cholinesterase (ChE) inhibitors with a biguanide skeletal structure.

\section{Materials and Methods}

2.1. Materials. The design and synthesis of selected prodrugs 1-3 (Figure 1) was carried out at the University of Eastern Finland and reported elsewhere [37, 38].

We decided to choose 3 sulfenamide metformin prodrugs differing in their structure (length of alkyl chain or presence of cyclohexyl moiety), as well as physicochemical properties (distribution coefficients in octanol/water, bioconversion rate $[37,38])$. The choice of prodrugs was made to find associations between the anticholinesterase activity and the structure of compounds. Not without significance were also previously conducted toxicity and biocompatibility studies (unpublished data). Studies concerning hemocompatibility of biguanides revealed that none of the tested prodrugs significantly affect the overall potential of clot formation and fibrinolysis (constant $\mathrm{CL}_{\mathrm{AUC}}$ ), which indicate that the tested compounds can be regarded as biocompatible towards plasma haemostasis. The obtained PT, APTT, and fibrinogen 


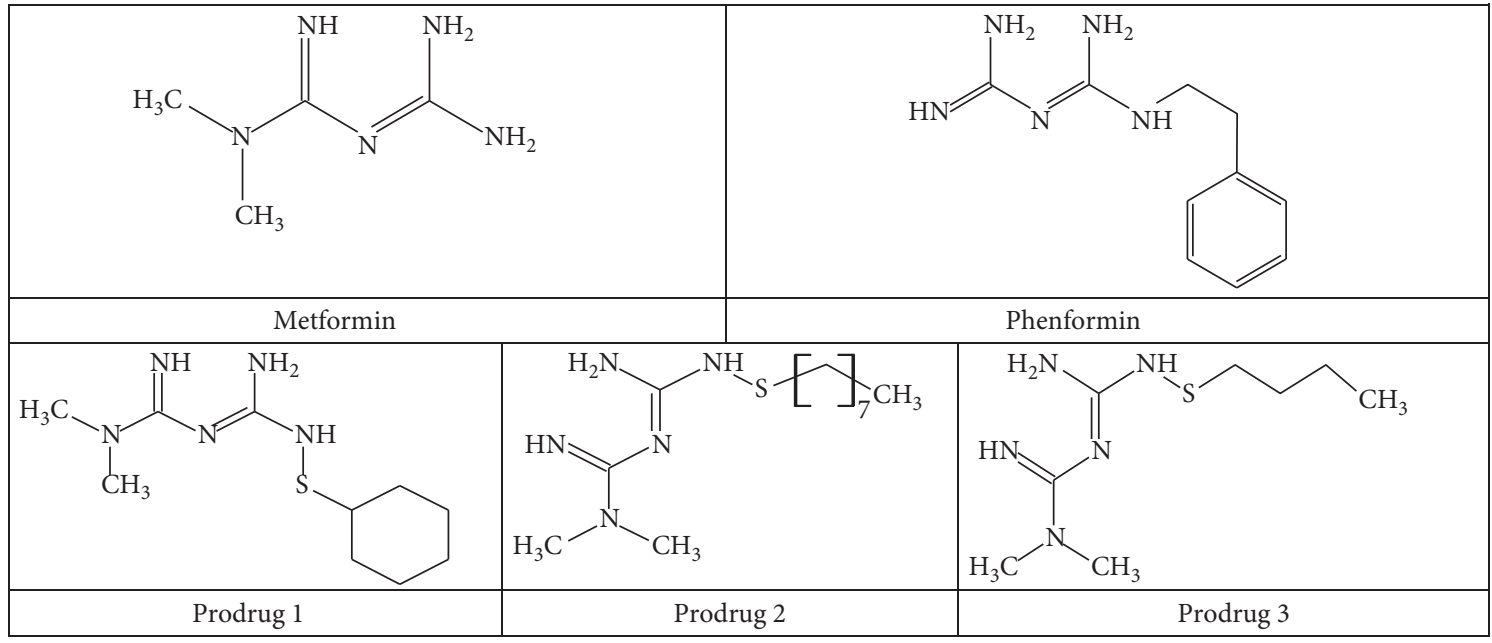

Figure 1: Chemical structure of biguanide derivatives: metformin, phenformin, and prodrugs 1-3.

concentrations demonstrate that the tested compounds do not interfere with the extrinsic and intrinsic coagulation pathways. The results of erythrotoxicity assays confirmed that the selected prodrugs are not toxic towards RBCs with exception of prodrug 2 at concentration of $1.5 \mu \mathrm{mol} / \mathrm{mL}$ (13\% hemolysis as compared to negative control).

The following reagents were used in this study: $0.9 \%$ $\mathrm{NaCl}(0.15 \mathrm{~mol} / \mathrm{L})$ (Chempur, Poland); $0.1 \mathrm{~mol} / \mathrm{L}$ phosphate buffer $\mathrm{pH}=7.0$ and $\mathrm{pH}=8.0$ (disodium phosphate, monosodium phosphate (Baker, Poland)); a stock solution of 5,5'dithiobisnitrobenzoic acid (DTNB; $0.01 \mathrm{~mol} / \mathrm{L}$ (Sigma Aldrich, St. Louis, MO, USA)) prepared in phosphate buffer at $\mathrm{pH}=7.0$; a stock aqueous solution of acetylthiocholine iodide $(21.67 \mathrm{mg} / \mathrm{mL}$ ) (Sigma Aldrich); and a stock aqueous solution of butyrylthiocholine iodide $(20.50 \mathrm{mg} / \mathrm{mL}$ ) (Sigma Aldrich). All solutions were stored as small samples at a temperature of $-30^{\circ} \mathrm{C}$ and before each experiment were restored at $37^{\circ} \mathrm{C}$ for 15 minutes.

2.2. Preparation of Biological Material. Blood samples were obtained from healthy donors from the Regional Blood Bank in Łódź, Poland (Regionalne Centrum Krwiodawstwa $i$ Krwiolecznictwa $w$ Łodzi). The blood was collected into vacuum tubes containing potassium versenate. Hemolysed human erythrocytes were used to determine AChE activity. Erythrocytes were separated from plasma by centrifugation $\left(3000 \times \mathrm{g}, 10 \mathrm{~min}, 20^{\circ} \mathrm{C}\right)$ with a Micro $22 \mathrm{R}$ centrifuge (Hettich Zentrifugen) and washed three times with $0.9 \%$ saline. Afterwards, red cells were hemolysed by freezing and stored at a temperature of $-30^{\circ} \mathrm{C}$; before each experiment, they were restored at $37^{\circ} \mathrm{C}$ for 15 minutes. Plasma for determination of BuChE activity was obtained by centrifuging the blood $\left(3000 \times \mathrm{g}, 10 \mathrm{~min}, 20^{\circ} \mathrm{C}\right)$.

The studies on biological material were approved by the Bioethics Committee of the Medical University of Lodz (RNN/109/16/KE).

2.3. Cholinesterase Inhibition. Prior to the study, probationary experiments were conducted to exclude potential interactions between sulfenamide prodrugs and reagents (DTNB, acetylthiocholine iodide, and butyrylthiocholine iodide). Spectrophotometric measurements of absorbance did not reveal any interactions between the reagents.

Acetylcholinesterase and butyrylcholinesterase activities were defined spectrophotometrically according to the Ellman method [39] with some modifications [40].

The experiments were performed on 96-well plates, and the absorbance was recorded at $\lambda=436 \mathrm{~nm}$ using a microplate reader (Synergy $^{\mathrm{TM}} \mathrm{H} 1$ reader (Bio-Tek Instruments Inc., USA)). The diluted solution of hemolysed erythrocytes or diluted plasma was incubated for 10 minutes $\left(37^{\circ} \mathrm{C}\right)$ with DTNB and tested compound at appropriate concentration, and the reaction was started by addition of substrate (acetylthiocholine iodide or butyrylthiocholine iodide). The absorbance was measured for five minutes, and the maximal velocity of the reaction was counted on the basis of changes in absorbance over time.

To validate the method, twelve control tests were conducted both for $\mathrm{AChE}$ and BuChE experiments. The coefficients of variability were counted $\left(W_{\mathrm{AChE}}=0.055\right.$, $W_{\mathrm{BuChE}}=0.072$, resp.).

2.4. Kinetic Parameter Estimation. The experiments were conducted using decreasing concentrations (2-, 3-, 5-, 10-, and 20-fold) of substrate (acetylthiocholine iodide or butyrylthiocholine iodide). The absorbance was recorded at $\lambda=436 \mathrm{~nm}$ using a CECIL 2021 spectrophotometer (CECIL Cambridge, UK) with a thermostatic water flow (temperature $\left.37^{\circ} \mathrm{C}\right)$.

2.5. Data Analysis. All values are expressed as mean \pm SD. All experiments (in duplicates) were conducted three times on different biological samples.

The $\mathrm{IC}_{50}$ value, defined as the drug concentration that inhibits $50 \%$ of the activity of an enzyme, was determined by linear regression $(y=a * x+b)$. AChE SI (selectivity index) was calculated by using the following formula: $\mathrm{SI}=\mathrm{IC}_{50}$ of $\mathrm{BChE} / \mathrm{IC}_{50}$ of $\mathrm{AChE}$. 


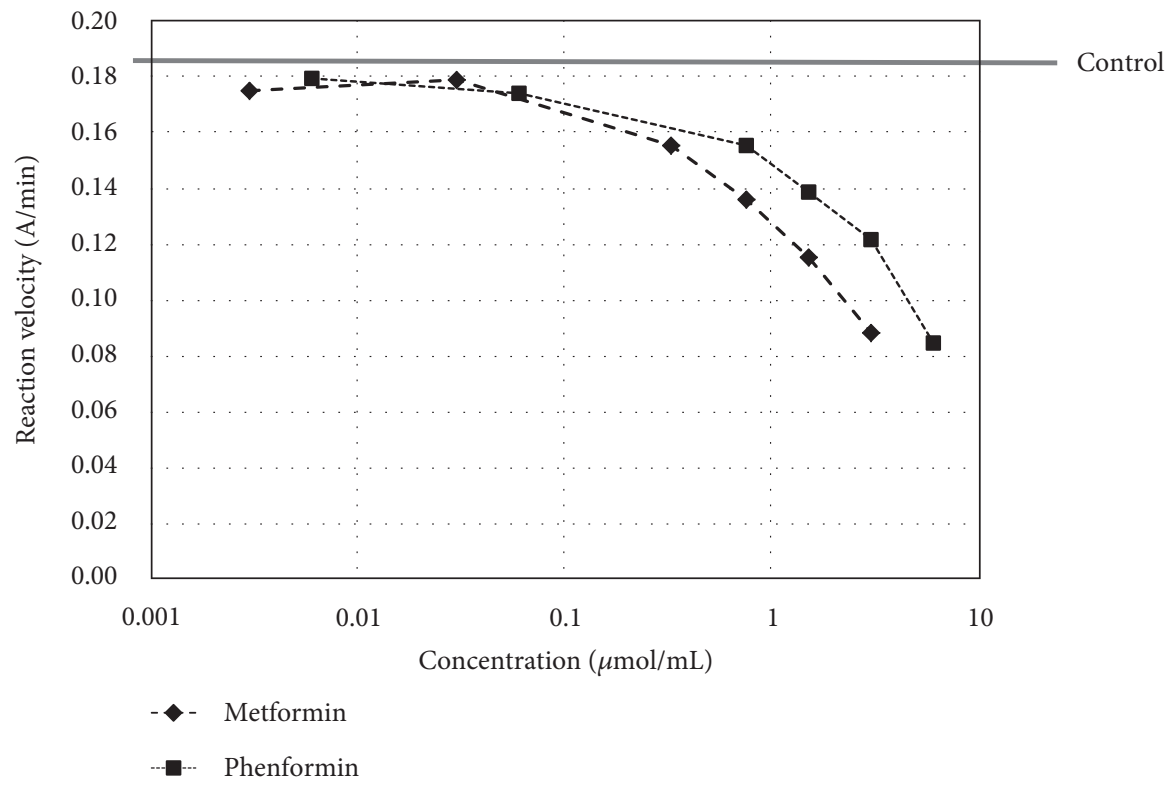

(a)

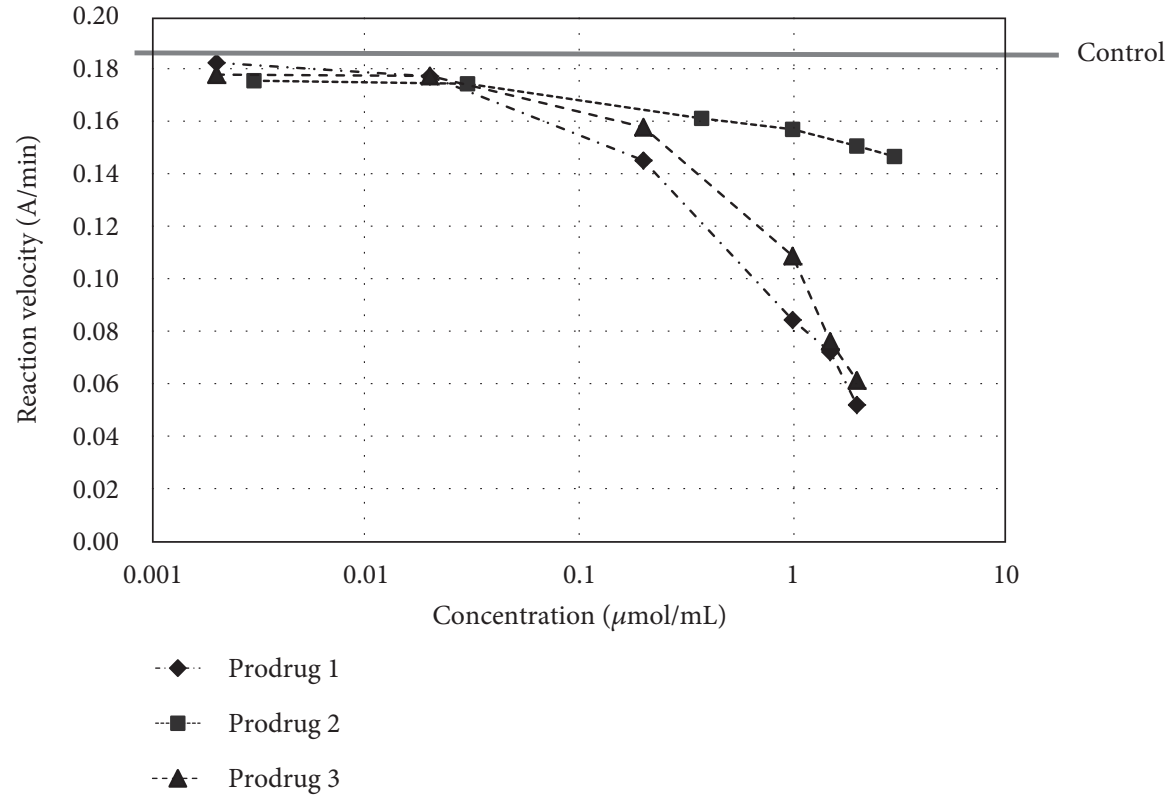

(b)

FIgURE 2: The effects of metformin and phenformin (a) and prodrugs 1, 2, and 3 (b) on AChE reaction velocity.

The calculations of maximal velocity $\left(V_{\max }\right)$ and the Michaelis constant $\left(K_{m}\right)$ were performed using linear regression (according to the Hanes-Woolf plot).

\section{Results}

3.1. Cholinesterase Activity. As presented in Figures 2 and 3, all examined compounds inhibited the activity of AChE; however, prodrug 2 only inhibited up to $21.2 \%$ at a concentration of $3 \mu \mathrm{mol} / \mathrm{mL}$. Similarly, in the case of BuChE, it was found that all compounds possess inhibitory properties except for metformin, which presented only weak anti-
BuChE activity. The percentages of AChE and BuChE inhibition and $\mathrm{IC}_{50}$ values were then calculated on the basis of the reaction velocity (Table 1 ).

Tacrine, the first compound recommended by the FDA for the treatment of $\mathrm{AD}$, was used to compare the obtained results [41]. Of the tested compounds, prodrug 1 demonstrated the highest activity towards human AChE $\left(\mathrm{IC}_{50}=0.89 \pm 0.157 \mu \mathrm{mol} / \mathrm{mL}\right)$; however, this activity is much lower than that of tacrine $\left(2.77 * 10^{-4} \pm 1.11 * 10^{-4} \mu \mathrm{mol} /\right.$ $\mathrm{mL})$. Prodrug 1 appeared to be the most active also against BuChE $\left(\mathrm{IC}_{50}=0.028 \pm 0.002 \mu \mathrm{mol} / \mathrm{mL}\right)$, whereas metformin inhibited BuChE so weakly (up to $26.4 \%$ at concentration 


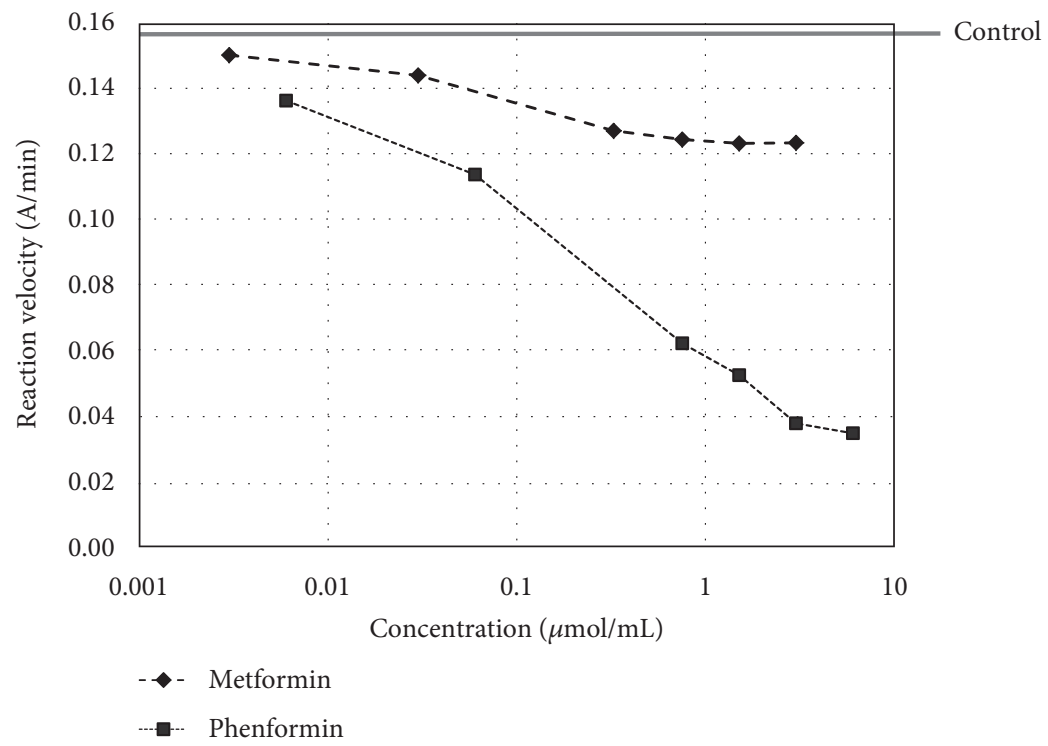

(a)

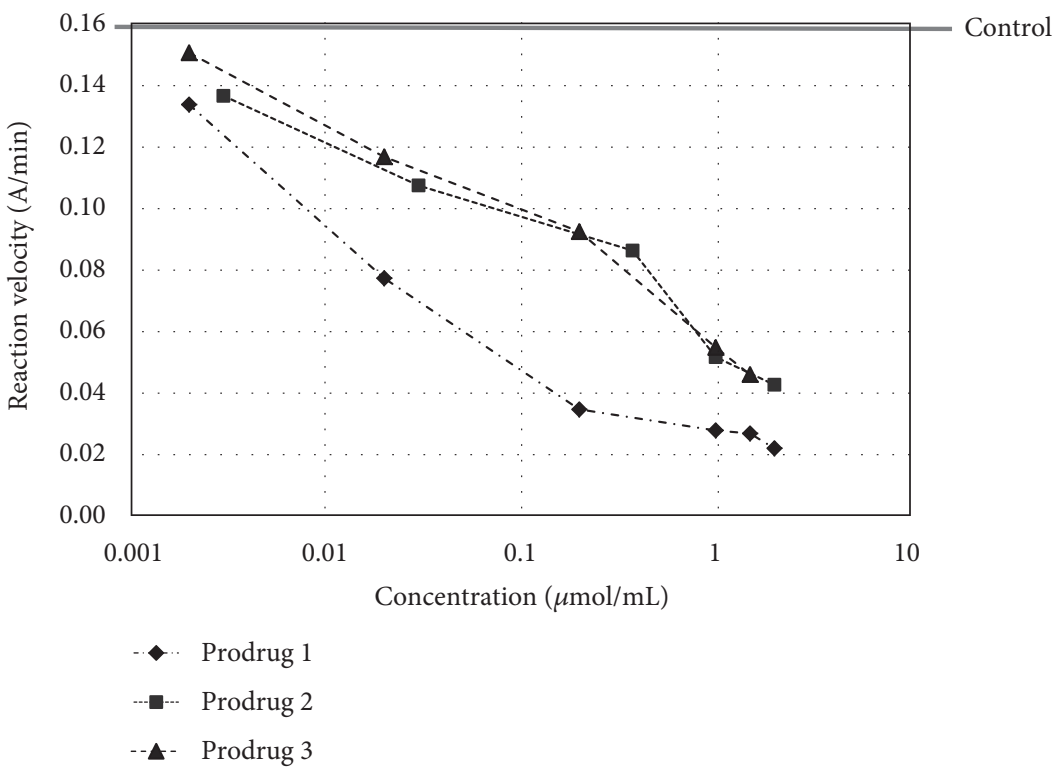

(b)

Figure 3: The effects of metformin and phenformin (a) and prodrugs 1, 2, and 3 (b) on BuChE reaction velocity. The velocity of pure BuChE was $0.160 \mathrm{~A} / \mathrm{min}$ (grey line). The results are presented as a mean of three independent experiments. Phenformin and prodrugs 1,2 , and 3 inhibited the reaction depending on their concentration.

of $3 \mu \mathrm{mol} / \mathrm{mL}$ ) that it did not allow $\mathrm{IC}_{50}$ to be calculated. On the basis of the calculated selectivity index (SI, Table 1), it was concluded that all other examined compounds exhibited higher selectivity toward BuChE than AChE.

3.2. Kinetic Parameters. In order to determine the type of inhibition, additional experiments were conducted with various concentrations of substrates, and the kinetic parameters of the enzymatic reactions were obtained by linear regression using the Hanes-Woolf equations. The Hanes-Woolf (half-reciprocal) plot of $[S]_{0} / v$ against $[S]_{0}$ gives intercepts at $K_{m} / V_{\max }$ and $K_{m}$ (Figure 4).
The summarized results of $K_{m}$ and $V_{\max }$ are presented in Table 2. In Tables S1 and S2 available online at https://doi.org/10.1155/2017/7303096 (Supplementary materials), we included detailed data on each individual reaction (equations, $R^{2}, K_{m}$, and $V_{\max }$ ).

Comparing the $K_{m}$ and $V_{\max }$ values of the results obtained for pure enzyme and tested compounds allowed the type of inhibition to be determined (Figure 4). In the case of AChE inhibition, both metformin and phenformin exhibited mixed inhibition, as $V_{\max (i)}\left(V_{\max }\right.$ of the reaction with inhibitor) significantly decreased in comparison with $V_{\max }$ while $K_{m(\mathrm{i})}\left(K_{m}\right.$ of the reaction with inhibitor) increased. Prodrugs 1 and 3 inhibited AChE noncompetitively (lack of 
TABLE 1: Effects of metformin, phenformin, and metformin prodrugs on the human erythrocyte acetylcholinesterase (AChE) and plasma butyrylcholinesterase (BuChE).

\begin{tabular}{|c|c|c|c|c|}
\hline \multirow{2}{*}{ Compound } & \multicolumn{2}{|c|}{$\mathrm{IC}_{50}[\mu \mathrm{mol} / \mathrm{mL}]$} & \multicolumn{2}{|c|}{ SI } \\
\hline & $\mathrm{AChE}$ & BuChE & AChE & $\mathrm{BuChE}$ \\
\hline Metformin & $2.350 \pm 0.122$ & $>1000.000^{\times}$ & $>425.531^{\times}$ & $<0.002^{\times}$ \\
\hline Phenformin & $4.940 \pm 0.575$ & $0.259 \pm 0.031$ & 0.052 & 19.073 \\
\hline Prodrug 1 & $0.890 \pm 0.157$ & $0.028 \pm 0.002$ & 0.031 & 31.786 \\
\hline Prodrug 2 & $>1000.000^{\times}$ & $0.184 \pm 0.014$ & $<1.840 * 10^{-4 \times}$ & $>5434.000^{\times}$ \\
\hline Prodrug 3 & $1.190 \pm 0.139$ & $0.205 \pm 0.029$ & 0.172 & 5.805 \\
\hline Tacrine* & $(2.770 \pm 1.11) * 10^{-4}$ & $(9.080 \pm 4.54) * 10^{-5}$ & 3.278 & 0.305 \\
\hline
\end{tabular}

The values are given as mean \pm standard deviation (SD) in three independent experiments. Values of $\mathrm{IC}_{50}$ for tacrine* were published previously [41]. The above values for tacrine were calculated from units $\mu \mathrm{g} / \mathrm{mL}(0.055 \pm 0.022$ and $0.018 \pm 0.009$, resp.). SI (selectivity index $)$-the AChE selectivity index is defined as $\mathrm{IC}_{50} \mathrm{BChE} / \mathrm{IC}_{50} \mathrm{AChE}$ affinity ratio. Selectivity for $\mathrm{BChE}$ is defined as $\mathrm{IC}_{50}(\mathrm{AChE}) / \mathrm{IC} \mathrm{C}_{50}(\mathrm{BChE})$. ${ }^{\times}$Theoretical values counted on the basis of extrapolated plots for metformin towards BuChE and prodrug 2 towards AChE. SI was calculated based on the theoretical $\mathrm{IC}_{50}$ values.

changes between $K_{m}$ and $K_{m(\mathrm{i})}$ and decreased $V_{\max (\mathrm{i})}$ value). Phenformin was shown to inhibit BuChE competitively, whereas noncompetitive inhibition was found for prodrug 3. In the case of prodrugs 1 and 2, the inhibition of $\mathrm{BuChE}$ was mixed type.

\section{Discussion}

A body of epidemiological data and pathophysiological evidence suggests the presence of various similarities between the two amyloidoses T2DM and AD. As noted in the Introduction, the two diseases present abnormal blood glucose levels, insulin resistance, inflammation, oxidative stress, and neurodegeneration $[42,43]$. Nowadays, three ChE inhibitors can be used to delay the symptomatic decline observed in patients with AD. These drugs include AChE-selective inhibitors, such as donepezil and galantamine, and dual-acting $\mathrm{AChE}$ and BuChE inhibitor, such as rivastigmine. The first FDA-approved AChE-nonselective inhibitor, tacrine, is no longer routinely prescribed due to a high incidence of hepatotoxicity [44].

Due to its pleiotropic activity, metformin, the most frequently administered oral antidiabetic drug, has shown promise in the treatment of neurodegenerative diseases $[28,29]$. For instance, Li et al. [33] determined AD-like brain changes in a mouse model of T2DM after treatment with metformin. The authors report that metformin administration for 18 weeks attenuated the increase of total tau, phospho-tau, and c-jun N-terminal kinase (JNK) activation. In addition, metformin weakened the reduction of synaptophysin, a synaptic protein, in mouse hippocampus. Furthermore, the results of this study imply that metformin did not attenuate the impairments of spatial learning and memory [33].

Despite its multidirectional pharmacological properties, metformin is characterized by unfavourable pharmacokinetics, as evidenced by slow and incomplete absorption from the intestine, resulting only in 50 to $60 \%$ bioavailability. In addition, intrasubject and intersubject variability has also been seen in its bioavailability, resulting in the response to metformin varying significantly, with approximately $30 \%$ of subjects receiving metformin being classified as nonresponders [45]. Therefore, there is a need to develop novel approaches, such as the synthesis of novel prodrugs of metformin in order to improve bioavailability [46].

No systematic study has yet examined the effects of metformin on ChEs. Therefore, the present study examines the ability of both recently synthesized prodrugs, clinically approved metformin and phenformin, which have been withdrawn from the market, to inhibit AChE and BuChE isolated from the human blood.

In spite of the results of Garcia-Ayllon et al. [12] and their statement that plasma AChE might have potential as an indicator of $\mathrm{AD}$ progress and prognosis, we presume that the inhibitory activities of biguanides might be transferred into brain AChE. Nevertheless, we are aware of the different sensitivities of brain and RBC AChE and differences in their glycosylation (dimeric AChE from red cell membranes is more heavily glycosylated than the tetrameric brain enzyme) [47] which may affect the inhibitory properties of studied compounds. Plasma BuChE was used because soluble, globular tetrameric BuChE in plasma as well as the membranebound forms in the muscle and brain are encoded by the same BuChE mRNA. Serum BuChE was used in this study since its kinetic parameters were earlier found to be comparable to those obtained with $\mathrm{BuChE}$ isolated from the human brain tissue [48].

Both enzymes possess the capacity to hydrolyze ACh; however, they differ genetically, structurally, and kinetically [44]. Although BuChE represents only $10 \%$ of total ChE activity in a healthy human brain, it has been reported that the importance of $\mathrm{BuChE}$ in cholinergic neurotransmission is likely to increase in AD. This has been accounted for the presence of decreased AChE activity during the progression of AD [44]. Studies of rivastigmine use indicate that cognitive improvements correlate independently with the inhibition of $\mathrm{AChE}$ and BuChE in the cerebrospinal fluid of AD patients, which suggest that the inhibition of both esterases, a dualacting property, is a highly desirable feature of AD therapy [49]. The importance of selective BuChE inhibition has further been shown using aged rats where BChE inhibition augmented ACh levels, increased cognitive function, and decreased amyloid deposits [50]. Since AChE activity decreases and BuChE activity increases as $\mathrm{AD}$ progresses, the inhibition of BuChE may become an increasingly important therapeutic target over time [43]. The principal objective 


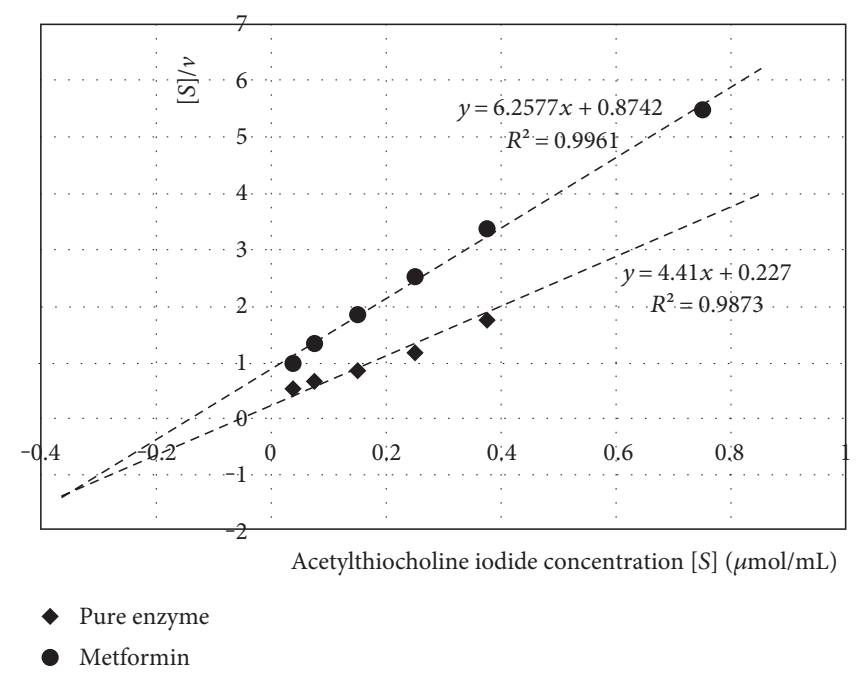

(a)

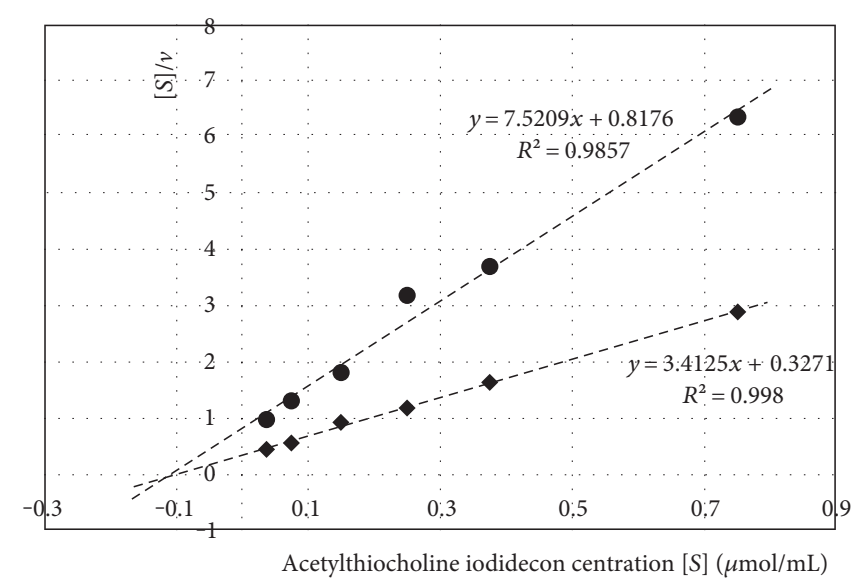

- Pure enzyme

- With prodrug 1

(b)

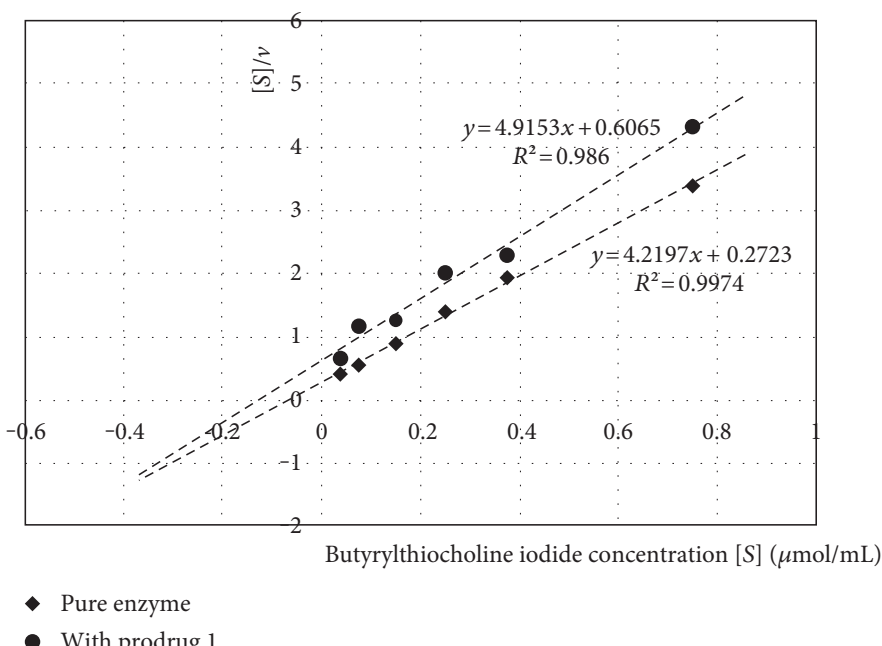

(c)

Figure 4: Hanes-Woolf's curves. (a) AChE and metformin at concentration of $2.35 \mu \mathrm{mol} / \mathrm{mL}$ (IC ${ }_{50}$ ), mixed-type inhibition; (b) AChE and prodrug 1 at concentration of $0.89 \mu \mathrm{mol} / \mathrm{mL}$ ( $\mathrm{IC}_{50}$ ), noncompetitive inhibition; (c) BuChE and prodrug 1 at concentration of $0.028 \mu \mathrm{mol} / \mathrm{mL}$ $\left(\mathrm{IC}_{50}\right)$, mixed-type inhibition. 
TABLE 2: Kinetic parameters of enzymatic reactions.

\begin{tabular}{|c|c|c|c|c|c|c|c|}
\hline \multirow{2}{*}{ Compound } & & \multicolumn{3}{|c|}{$\mathrm{AChE}$} & \multicolumn{3}{|c|}{$\mathrm{BuChE}$} \\
\hline & & $K_{m}[\mu \mathrm{mol} / \mathrm{mL}]$ & $V_{\max }[\mathrm{A} / \mathrm{min}]$ & $\mathrm{I}$ & $K_{m}[\mu \mathrm{mol} / \mathrm{mL}]$ & $V_{\max }[\mathrm{A} / \mathrm{min}]$ & $\mathrm{I}$ \\
\hline \multirow{2}{*}{ Metformin } & $\mathrm{A}$ & $0.056 \pm 0.012$ & $0.224 \pm 0.002$ & \multirow{2}{*}{ M } & NS & NS & \multirow{2}{*}{ - } \\
\hline & $\mathrm{B}$ & $0.167 \pm 0.024$ & $0.164 \pm 0.004$ & & NS & NS & \\
\hline \multirow{2}{*}{ Phenformin } & $\mathrm{A}$ & $0.056 \pm 0.028$ & $0.230 \pm 0.017$ & \multirow{2}{*}{$\mathrm{M}$} & $0.037 \pm 0.015$ & $0.159 \pm 0.045$ & \multirow{2}{*}{$\mathrm{C}$} \\
\hline & $\mathrm{B}$ & $0.083 \pm 0.047$ & $0.127 \pm 0.003$ & & $0.152 \pm 0.029$ & $0.167 \pm 0.039$ & \\
\hline \multirow{2}{*}{ Prodrug 1} & $\bar{A}$ & $0.091 \pm 0.004$ & $0.292 \pm 0.008$ & \multirow{2}{*}{$\mathrm{NC}$} & $0.044 \pm 0.025$ & $0.222 \pm 0.047$ & \multirow{2}{*}{ M } \\
\hline & $\mathrm{B}$ & $0.097 \pm 0.018$ & $0.132 \pm 0.003$ & & $0.087 \pm 0.047$ & $0.194 \pm 0.008$ & \\
\hline \multirow{2}{*}{ Prodrug 2} & $\mathrm{~A}$ & NS & NS & \multirow{2}{*}{-} & $0.046 \pm 0.020$ & $0.202 \pm 0.019$ & \multirow{2}{*}{$\mathrm{M}$} \\
\hline & $\mathrm{B}$ & NS & NS & & $0.078 \pm 0.024$ & $0.091 \pm 0.015$ & \\
\hline \multirow{2}{*}{ Prodrug 3} & $\mathrm{~A}$ & $0.089 \pm 0.003$ & $0.290 \pm 0.002$ & \multirow{2}{*}{$\mathrm{NC}$} & $0.045 \pm 0.021$ & $0.202 \pm 0.019$ & \multirow{2}{*}{$\mathrm{NC}$} \\
\hline & $\mathrm{B}$ & $0.078 \pm 0.012$ & $0.159 \pm 0.026$ & & $0.054 \pm 0.021$ & $0.117 \pm 0.022$ & \\
\hline
\end{tabular}

The values are given as mean \pm standard deviation (SD) in 3 independent experiments. NS-the kinetic parameters were not estimated. A-kinetic parameters for pure enzyme $\left(K_{m}, V_{\max }\right)$; B-kinetic parameters of tested compounds (inhibitors) $\left(\mathrm{IC}_{50}\right.$ concentrations) $\left(K_{m(\mathrm{i})}\right.$, $\left.V_{\max (\mathrm{i})}\right)$. I-type of inhibition, M- mixed type, NC-inhibition noncompetitive, $\mathrm{C}$-inhibition competitive.

of our studies was to evaluate in a systematic study the mechanism of AChE inhibition by metformin, as even the state-of-the-art scientific literature lacks such knowledge. Our goal was also to evaluate the effects of biguanides on BuChE activity, which now has emerged as important issue in $\mathrm{AD}$ treatment.

Our findings indicate that metformin inhibits $50 \%$ of AChE activity at a concentration of $2.35 \pm 0.122 \mu \mathrm{mol} / \mathrm{mL}$ and that it appears to be selective towards AChE, since it had very weak anti-BuChE activity (Table 1). This finding is supported by several studies. For instance, Bhutada et al. [51] have tested the influence of berberine, an isoquinolone alkaloid, against cognitive dysfunction in streptozotocininduced diabetic rats. The authors assessed lipid peroxidation and glutathione levels as parameters of oxidative stress and $\mathrm{ChE}$ activity as a marker of cholinergic function. Induction of diabetes in rats contributed to a severe impairment in learning and memory associated with increased lipid peroxidation and ChE activity. Apart from berberine, the authors examined the influence of metformin and vitamin C. It was found that chronic treatment (30 days) with metformin at a dose of $500 \mathrm{mg} / \mathrm{kg}$ improved cognitive performance and reduced oxidative stress and ChE activity. No statistically significant effect on ChE activity was noted in the case of shortterm administration of metformin (five days) [51]. Similarly, Saliua et al. [52] confirmed that metformin at a dose of $500 \mathrm{mg} / \mathrm{kg}$ significantly decreased AChE activity in the brain of streptozocin-induced diabetic rats [52]. Therefore, we may presume that the inhibitory effects of metformin on this key enzyme linked with neurodegeneration may be responsible for preventing cholinergic dysfunction in T2DM.

In contrast, some studies do not record any anti-ChE activity for metformin. For example, Arafa et al. [53] examined the effect of the antidiabetic medications canagliflozin and metformin on the levels of cortical neurotransmitters and ChE activity in a diabetic rat model. The authors report that the diabetic group exhibited a significant increase in AChE activity and a decrease in monoamine and amino acid neurotransmitter levels. A two-week treatment with canagliflozin led to decreased AChE activity, whereas the same treatment with metformin did not demonstrate significant influence on the enzyme activity [53]. Another study by Mostafa et al. found the application of metformin at doses of 100 and $300 \mathrm{mg} / \mathrm{kg}$ to have no effect on reduction of tissue AChE activity in a scopolamine-induced memory deficit rat model [36]. However, in both of these studies, the dose of metformin administered to animals was lower $(100-300 \mathrm{mg} / \mathrm{kg}$ ) than in those which report an influence on AChE activity (500 mg/kg).

In the present study, phenformin exhibited the lowest level of inhibition towards both $\mathrm{ChE}$ forms (the highest $\mathrm{IC}_{50}$ values in Table 1). Of the tested prodrugs, the sulfenamide with a cyclohexyl tail (prodrug 1) appeared to be the most active inhibitor for both AChE and BuChE $\left(\mathrm{IC}_{50}=890\right.$ and $28 \mathrm{nmol} / \mathrm{mL}$, resp.) thus demonstrating a dual-binding property that favours the inhibition of BuChE. Furthermore, these values are over 3000-fold higher for $\mathrm{AChE}$, and 300-fold higher for BuChE, compared to those of tacrine, an AChE-nonselective inhibitor used clinically until 2013. With this in mind, it should be mentioned that compounds of natural origin with potential application as anti-AD agents are also much less potent than tacrine [39].

The sulfenamide prodrug with an octyl tail (prodrug 2) was the only compound which inhibited BuChE at nanomolar concentrations ( $184 \mathrm{nmol} / \mathrm{mL}$, Table 1$)$ but had very weak anti-AChE activity $\left(\mathrm{IC}_{50}>1000.0 \mu \mathrm{mol} / \mathrm{mL}\right)$. Therefore, this prodrug can be regarded as a BuChE-selective inhibitor. BuChE selectivity appears to be important not only in AD but also in regard to inflammation, oxidative stress, and lipid metabolism [54]. For instance, it has been shown that streptozotocin-induced diabetic animals had dyslipidemia, increased plasma lipid peroxide content, decreased circulating plasma superoxide dismutase activity, and increased BuChE level [55]. In addition, elevated BuChE activity can lead to decreased ACh levels, thereby resulting in low-grade systemic inflammation [55]. Furthermore, there are also some studies that suggest that selective, reversible inhibition of brain BuChE may serve as a treatment for $\mathrm{AD}$, improving cognition and modulating neuropathological AD markers such as inflammation [56]. 
Curiously, the sulfenamide prodrug with a shorter butyl tail (prodrug 3) was not selective towards $\mathrm{BuChE}$ and it had highest $\mathrm{IC}_{50}$ value towards both enzymes $(1190 \mathrm{nmol} / \mathrm{mL}$ and $205 \mathrm{nmol} / \mathrm{mL}$, resp., Table 1). Taken together, these results indicate that attaching a long alkyl or bulkier cyclohexyl chain to the opposite part of dimethyl group in metformin may improve its inhibition and selectivity towards BuChE.

Taking into consideration the type of inhibition by which prodrugs 1 and 3 inhibited AChE (noncompetitive, Table 2), our results illustrate that the prodrug molecules are able to bind to a site other than the catalytic active site (CAS) of the enzyme. It has been recognized that AChE has a peripheral anionic site (PAS) located at the aromatic-lined entrance of a narrow groove, on the bottom of which the CAS is located [57-59]. Therefore, it is likely that sulfenamide prodrugs of metformin can bind only to the PAS, which changes the enzyme's three-dimensional structure so that the CAS can still bind to substrates with the usual affinity; however, this is no longer the optimal arrangement for stabilizing the transition state and catalyzing the reaction. The ability to bind to the PAS arises most probably from the same structural properties (long or bulky side chain) that drive these prodrugs from AChE towards BuChE, since metformin and phenformin inhibited AChE in a mixed-type manner (Table 2), and while the smaller compound, metformin, inhibited BuChE only weakly (Table 1), phenformin was relatively more BuChE-selective. Phenformin was also the only compound which competitively inhibited BuChE (Table 2), which means that it was the only one that was able to compete with the substrate for the CAS of this enzyme. The bulkier sulfenamide prodrugs 1 and 2 inhibited BuChE with mixed-type manner and the smallest sulfenamide prodrug 3 did so purely noncompetitively. This is consistent with other studies that have claimed that the PAS is smaller in BuChE than in AChE [57].

When considering the properties of the prodrugs, the octylsulfenyl prodrug (2) is the only compound that has been shown to be stable both in vitro and in vivo [38], while both cyclohexyl and butyl sulfenyl prodrugs (1 and 3) have shown to be bioconverted quickly not only in vitro in the presence of free thiols but also in vivo in cells such as erythrocytes which are rich in endogenous thiol $[37,38,60]$. Therefore, prodrug 1 and 3 are less likely to be delivered intact across the bloodbrain barrier (BBB), while prodrug 2 is more likely to reach the extracellular fluids (ECF) and the synaptic clefts within the brain, where the ChEs are located. However, even though prodrugs 1 and 3 are bioconverted to metformin soon after their oral absorption [37, 38], they can improve the oral bioavailability of metformin; according to these results, they can therefore be considered as prodrugs of a selective AChE inhibitor (metformin).

Taken together, the results gained in this study offer encouragement in the development of a new class of selective and unselective $\mathrm{ChE}$ inhibitors with a biguanide backbone structure. If a prodrug property is not desired, the linking sulphur atom can also be left out to stabilize the structure. Increasing the chain length and size, it is possible to achieve BuChE-selective inhibitors, while the presence of small side chains on both sides of the biguanides ensures the dual binding property. The use of selective $\mathrm{ChE}$ inhibitors would allow more detailed study of the function and role of AChE and $\mathrm{BuChE}$ in $\mathrm{AD}$ in the future. On the other hand, the capacity for simultaneous interaction with PAS and resulting dualbinding potential to both ChEs is an attractive property in the rational design of $\mathrm{ChE}$ inhibitors, since binding to PAS has also been associated with an ability to interfere with amyloid- $\beta$ deposition and aggregation [61].

\section{Summary}

The aim of the present in vitro study was to determine the inhibitory properties of metformin and its sulfenamide prodrugs towards ChEs. Metformin was found to moderately inhibit the activity of AChE in a mixed-type inhibition and to have very weak anti-BuChE activity. These results may contribute to a better understanding of the neuroprotective role of the most frequently used antidiabetic drug, metformin. Conversely, a sulfenamide prodrug containing an eight-carbon alkyl chain presented weak activity towards AChE inhibition, but nanomolar inhibition towards BuChE. Two other sulfenamide prodrugs inhibited $\mathrm{AChE}$ and $\mathrm{BuChE}$ noncompetitively or with a mixed-type pattern. Therefore, these results together indicate that the bulky side chains of biguanides are most likely to interact with the PAS of AChE and drive the compounds towards BuChE-selective inhibition, while drugs with smaller side chains are more likely to retain the noncompetitive inhibitory activity for both enzymes and thus have dual-binding properties. Thus, biguanides might have potential in preventing brain disorders associated with diabetes complications in future.

\section{Conflicts of Interest}

The authors declare that they have no conflicts of interest.

\section{Acknowledgments}

The work is funded by the National Science Centre in Poland (Research Project no. 2016/21/D/NZ7/01548), the Medical University of Lodz (Grant no. 503/3-015-01/503-31-004), and the Academy of Finland (Grant no. 294227).

\section{References}

[1] S. M. Setter, J. L. Iltz, J. Thams, and R. K. Campbell, "Metformin hydrochloride in the treatment of type 2 diabetes mellitus: a clinical review with a focus on dual therapy," Clinical Therapeutics, vol. 25, pp. 2991-3026, 2003.

[2] Z. Zhanga, P. Fang, M. Shia, Y. Zhu, and P. Bo, "Elevated galanin may predict the risk of type 2 diabetes mellitus for development of Alzheimer's disease," Mechanisms of Ageing and Development, vol. 150, pp. 20-26, 2015.

[3] G. J. Biessels, S. Staekenborg, E. Brunner, C. Brayne, and P. Scheltens, "Risk of dementia in diabetes mellitus: a systematic review," Lancet Neurology, vol. 5, pp. 64-74, 2006.

[4] D. Kopf and L. Frölich, "Risk of incident Alzheimer's disease in diabetic patients: a systematic review of prospective trials," Journal of Alzheimer's Disease, vol. 16, pp. 677-685, 2009. 
[5] R. Peila, B. L. Rodriguez, and L. J. Launer, "Type 2 diabetes, APOE gene, and the risk for dementia and related pathologies: the Honolulu-Asia aging study," Diabetes, vol. 51, pp. 12561262, 2002.

[6] Z. Arvanitakis, R. S. Wilson, J. L. Bienias, D. A. Evans, and D. A. Bennett, "Diabetes mellitus and risk of Alzheimer disease and decline in cognitive function," Archives of Neurology, vol. 61, pp. 661-666, 2004.

[7] G. V. Johnson and W. H. Stoothoff, "Tau phosphorylation in neuronal cell function and dysfunction," Journal of Cell Science, vol. 117, pp. 5721-5729, 2004.

[8] M. M. Mesulam and M. A. Morán, "Cholinesterases within neurofibrillary tangles related to age and Alzheimer's disease," Annals of Neurology, vol. 22, pp. 223-228, 1987.

[9] J. Ulrich, W. Meier-Ruge, A. Probst, E. Meier, and S. Ipsen, "Senile plaques: staining for acetylcholinesterase and A4 protein: a comparative study in the hippocampus and entorhinal cortex," Acta Neuropathologica, vol. 80, pp. 624-628, 1990.

[10] M. S. García-Ayllón, D. H. Small, J. Avila, and J. Sáez-Valero, "Revisiting the role of acetylcholinesterase in Alzheimer's disease: cross-talk with P-tau and $\beta$-amyloid," Frontiers in Molecular Neuroscience, vol. 4, p. 22, 2011.

[11] A. Imramovsky, S. Stepankova, J. Vanco et al., "Acetylcholinesterase-inhibiting activity of salicylanilide $N$-alkylcarbamates and their molecular docking," Molecules, vol. 17, pp. 1014210158, 2012.

[12] M. S. Garcia-Ayllon, I. Riba-Llena, C. Serra-Basante, J. Alom, R. Boopathy, and J. Saez-Valero, "Altered levels of acetylcholinesterase in Alzheimer plasma," PloS One, vol. 5, no. 1, article e8701, 2010.

[13] E. L. Abnera, P. T. Nelson, R. J. Kryscio et al., "Diabetes is associated with cerebrovascular but not Alzheimer's disease neuropathology," Alzheimer's \& Dementia, vol. 12, pp. 882$889,2016$.

[14] R. O. Domínguez, M. A. Pagano, E. R. Marschoff, S. E. González, M. G. Repetto, and J. A. Serra, "Alzheimer disease and cognitive impairment associated with diabetes mellitus type 2: associations and a hypothesis," Neurología, vol. 29, pp. 567-572, 2014.

[15] A. Ciudin, "Diabetes mellitus tipo 2 yenfermedad de Alzheimer: una relación para no olvidar," Endocrinología y Nutrición, vol. 63, pp. 191-193, 2016.

[16] A. Apostolatos, S. Song, S. Acosta et al., "Insulin promotes neuronal survival via the alternatively spliced protein kinase CdeltaII isoform," Journal of Biological Chemistry, vol. 287, pp. 9299-9310, 2012.

[17] V. M. Lourenco, S. T. Ferreira, and F. G. De Felice, "Neuronal stress signaling and eIF2a phosphorylation as molecular links between Alzheimer's disease and diabetes," Progress in Neurobiology, vol. 129, pp. 37-57, 2015.

[18] L. Frolich, D. Blum-Degen, H. G. Bernstein et al., "Brain insulin and insulin receptors in aging and sporadic Alzheimer's disease," Journal of Neural Transmission, vol. 105, pp. 423438, 1998.

[19] M. Schubert, D. P. Brazil, D. J. Burks et al., "Insulin receptor substrate-2 deficiency impairs brain growth and promotes tau phosphorylation," Journal of Neuroscience, vol. 23, pp. 7084-7092, 2003.

[20] G. Verdile, S. J. Fuller, and R. N. Martins, "The role of type 2 diabetes in neurodegeneration," Neurobiology of Disease, vol. 84, pp. 22-38, 2015.
[21] C. A. Abbott, M. I. Mackness, S. Kumar et al., "Relationship between serum butyrylcholinesterase activity, hypertriglyceridemia and insulin sensitivity in diabetes mellitus," Clinical Science, vol. 85, pp. 7-81, 1993.

[22] T. Iwasaki, M. Yoneda, A. Nakajima, and Y. Terauchi, "Serum butyrylcholinesterase is strongly associated with adiposity, the serum lipid profile and insulin resistance," Internal Medicine, vol. 46, pp. 1633-1639, 2007.

[23] S. Shahmohamadnejad, A. Vaisi-Raygani, Y. Shakiba et al., "Association between butyrylcholinesterase activity and phenotypes, paraoxonase192 rs662 gene polymorphism and their enzymatic activity with severity of rheumatoid arthritis: correlation with systemic inflammatory markers and oxidative stress, preliminary report," Clinical Biochemistry, vol. 48, pp. 63-69, 2015.

[24] M. K. Song, D. S. Bischoff, A. M. Song, K. Uyemura, and D. T. Yamaguchi, "Metabolic relationship between diabetes and Alzheimer's disease affected by cyclo(his-pro) plus zinc treatment," Biochimica et Biophysica Acta Clinical, vol. 7, pp. 41-54, 2016.

[25] A. Kuhad, R. Sethi, and K. Chopra, "Lycopene attenuates diabetes-associated cognitive decline in rats," Life Sciences, vol. 83, pp. 128-134, 2008.

[26] N. H. Greig, T. Utsuki, D. K. Ingram, Y. Wang, G. Pepeu, and C. Scall, "Selective butyrylcholinesterase inhibition elevated brain acetylcholine, augments learning and lowers Alzheimer beta-amyloid peptide in rodent," Proceedings of the National Academy of Sciences of the United States of America, vol. 102, pp. 17213-17218, 2005.

[27] K. Mahmood, M. Naeem, and N. A. Rahimnajjad, "Metformin: the hidden chronicles of a magic drug," European Journal of Internal Medicine, vol. 24, pp. 20-26, 2013.

[28] J. A. Luchsinger, M. X. Tang, S. Shea, and R. Mayeux, "Hyperinsulinemia and risk of Alzheimer disease," Neurology, vol. 63, pp. 1187-1192, 2004.

[29] February 2017, http://clinicaltrials.gov.

[30] A. R. Mendelsohn and J. W. Larrick, "Rapamycin as an antiaging therapeutic? Targeting mammalian target of rapamycin to treat Hutchinson-Gilford progeria and neurodegenerative diseases," Rejuvenation Research, vol. 14, pp. 437-441, 2011.

[31] P. Picone, D. Nuzzo, L. Caruana et al., "Metformin increases APP expression and processing via oxidative stress, mitochondrial dysfunction and NF- $\kappa \mathrm{B}$ activation: use of insulin to attenuate metformin's effects," Biochimica et Biophysica Acta, vol. 1853, pp. 1046-1059, 2015.

[32] P. Picone, S. Vilasi, F. Librizzi et al., "Biological and biophysics aspects of metformin-induced effects: cortex mitochondrial dysfunction and promotion of toxic amyloid pre-fibrillar aggregates," Aging, vol. 8, pp. 1718-1720, 2016.

[33] J. Li, J. Deng, and Z. Zuo, "Metformin attenuates Alzheimer's disease-like neuropathology in obese, leptin-resistant mice," Pharmacology Biochemistry and Behavior, vol. 101, pp. 564574, 2012.

[34] Y. Chen, K. Zhou, R. Wang et al., "Antidiabetic drug metformin (Glucophage ${ }^{\mathrm{R}}$ ) increases biogenesis of Alzheimer's amyloid peptides via up-regulating BACE1 transcription," Proceedings of the National Academy of Sciences of the United States of America, vol. 106, no. 10, pp. 3907-3912, 2009.

[35] M. M. Hettich, F. Mattes, D. P. Ryan et al., "The antidiabetic drug metformin reduces BACE1 protein level by 
interfering with the MID1 complex," PloS One, vol. 9, article e02420, 2014.

[36] D. K. Mostafa, C. A. Ismail, and D. A. Ghareeb, "Differential metformin dose-dependent effects on cognition in rats: role of Akt," Psychopharmacology, vol. 233, pp. 2513-2524, 2016.

[37] K. M. Huttunen, J. Leppänen, K. Laine, J. Vepsäläinen, and J. Rautio, "Convenient microwave-assisted synthesis of lipophilic sulfonamide prodrugs of metformin," European Journal of Pharmaceutical Sciences, vol. 49, pp. 624-628, 2013.

[38] K. M. Huttunen, J. Leppänen, J. Vepsäläinen, J. Sirviö, K. Laine, and J. Rautio, "In vitro and in vivo evaluation of a sulfenamide prodrug of basic metformin," Journal of Pharmaceutical Sciences, vol. 10, pp. 2854-2860, 2012.

[39] G. L. Ellman, K. D. Courtney, and R. M. Featherstone, “A new and rapid colorimetric determination of acetylcholinesterase activity," Biochemical Pharmacology, vol. 7, pp. 88-90, 1961.

[40] F. Worek, U. Mast, D. Kiderlen, C. Diepold, and P. Eyer, "Improved determination of acetylcholinesterase activity in human whole blood," Clinica Chimica Acta, vol. 288, pp. 73-90, 1999.

[41] Ł. Kuźma, H. Wysokińska, J. Sikora, P. Olszewska, E. Mikiciuk-Olasik, and P. Szymański, "Taxodione and extracts from Salvia austriaca roots as human cholinesterase inhibitors," Phytotherapy Research, vol. 30, pp. 234-242, 2016.

[42] M. Marszałek, "Diabetes type 2 and Alzheimer disease - one or two diseases? Mechanisms of association," Postępy Higieny I Medycyny Doświadczalnej, vol. 67, pp. 653-671, 2013.

[43] M. Markowicz-Piasecka, J. Sikora, A. Szydłowska, A. Skupień, E. Mikiciuk-Olasik, and K. M. Huttunen, "Metformin - a future therapy for neurodegenerative diseases," Pharmaceutical Research, pp. 1-14, 2017.

[44] G. T. Grossberg, "Cholinesterase inhibitors for the treatment of Alzheimer's disease: getting on and staying on," Current Therapy Research, vol. 64, pp. 216-235, 2003.

[45] S. L. Stocker, K. M. Morrissey, S. W. Yee et al., "The effect of novel promoter variants in MATE1 and MATE2 on the pharmacokinetics and pharmacodynamics of metformin," Clinical Pharmacology and Therapeutics, vol. 93, pp. 186-194, 2013.

[46] J. Rautio, M. Vernerová, I. Aufderhaar, and K. M. Huttunen, "Glutathione-S-transferase selective release of metformin from its sulfonamide prodrug," Bioorganic and Medicinal Chemistry Letters, vol. 24, pp. 5034-5036, 2014.

[47] J. Liao, H. Heider, M. C. Sun, and U. Brodbeck, "Different glycosylation in acetylcholinesterases from mammalian brain and erythrocytes," Journal of Neurochemistry, vol. 58, no. 4, pp. 1230-1238, 1992.

[48] S. Darvesh, G. A. Reid, and E. Martin, "Biochemical and histochemical comparison of cholinesterases in normal and Alzheimer brain tissues," Current Alzheimer Research, vol. 5, pp. 386-400, 2010.

[49] E. Giacobini, R. Spiegel, and A. Enz, "Inhibition of acetyl- and butyryl-cholinesterase in the cerebrospinal fluid of patients with Alzheimer's disease by rivastigmine: correlation with cognitive benefit," Journal of Neural Transmission, vol. 109, pp. 1053-1065, 2002.

[50] N. H. Greig, T. Utsuki, D. K. Ingram et al., "Selective butyrylcholinesterase inhibition elevates brain acetylcholine, augments learning and lowers Alzheimer $\beta$-amyloid peptide in rodent," Proceedings of the National Academy of Sciences of the United States of America, vol. 102, pp. 17213-17218, 2005.
[51] P. Bhutada, Y. Mundhada, K. Bansoda et al., "Protection of cholinergic and antioxidant system contributes to the effect of berberine ameliorating memory dysfunction in rat model of streptozotocin-induced diabetes," Behavioural Brain Research, vol. 220, pp. 30-41, 2011.

[52] J. A. Saliua, G. Obohb, O. S. Omojokun et al., "Effect of dietary supplementation of padauk (Pterocarpus soyauxii) leaf on high fat diet/streptozotocin induced diabetes in rats' brain and platelets," Biomedicine \& Pharmacotherapy, vol. 84, pp. 1194-1201, 2016.

[53] N. M. S. Arafa, M. Mohamed-Assem, and S. A. Mubarak Al-Azimi, "Effect of canagliflozin and metformin on cortical neurotransmitters in a diabetic rat model," Chemico-Biological Interactions, vol. 258, pp. 78-88, 2016.

[54] G. R. Sridhar, A. A. Rao, K. Srinivas et al., "Butyrylcholinesterase in metabolic syndrome," Medical Hypotheses, vol. 75, pp. 648-651, 2010.

[55] A. A. Rao, C. Siva Reddy, G. R. Sridhar, A. Annapurna, T. Hanuman, and M. Prameela, "Enhanced butyrylcholinesterase activity may be the common link in triggering low-grade systemic inflammation and decrease in cognitive function in diabetes mellitus and Alzheimer's disease," Current Nutrition and Food Science, vol. 4, pp. 213-216, 2008.

[56] N. H. Greig, T. Utsuki, D. K. Ingram et al., "Selective butyrylcholinesterase inhibition elevates brain acetylcholine, augments learning and lowers Alzheimer beta-amyloid peptide in rodent," Proceedings of the National Academy of Sciences of the United States of America, vol. 102, pp. 17213-17218, 2005.

[57] M. Bajda, A. Więckowska, M. Hebda, N. Guzior, C. A. Sotriffer, and B. Malawska, "Structure-based search for new inhibitors of cholinesterases," International Journal of Molecular Science, vol. 14, pp. 5608-5632, 2013.

[58] K. R. Valasani, M. O. Chaney, V. W. Day, and S. Shidu Yan, "Acetylcholinesterase inhibitors: structure based design, synthesis pharmacophore modeling, and virtual screening," Journal of Chemical Information and Modelling, vol. 53, pp. 2033-2046, 2013.

[59] M. B. Colovic, D. Z. Krstic, T. D. Lazarevic-Pasti, A. M. Bondzic, and V. M. Vasic, "Acetylcholinesterase inhibitors: pharmacology and toxicology," Current Neuropharmacology, vol. 11, pp. 215-335, 2013.

[60] L. Peura and K. M. Huttunen, "Sustained release of metformin via red blood cell accumulated sulfenamide prodrug," Journal of Pharmaceutical Sciences, vol. 103, pp. 2207-2210, 2014.

[61] S. Gupta and G. C. Mohan, "Dual binding site and selective acetylcholinesterase inhibitors derived from integrated pharmacophore models and sequential virtual screening," BioMed Research International, vol. 2014, Article ID 291214, 21 pages, 2014. 


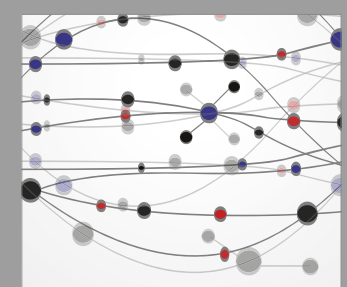

The Scientific World Journal
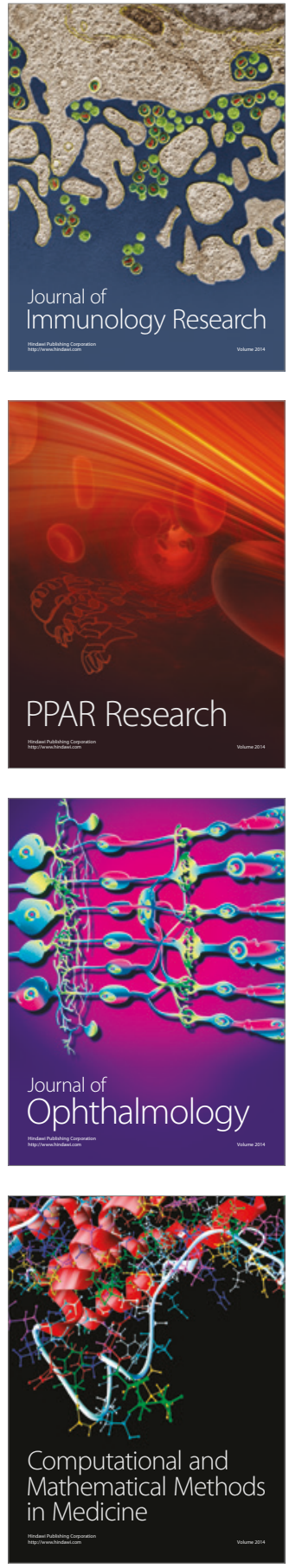

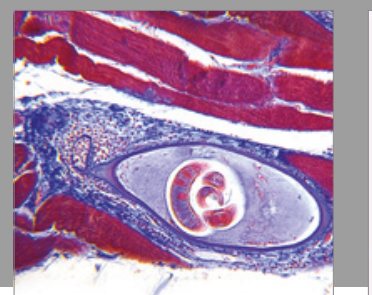

Gastroenterology Research and Practice
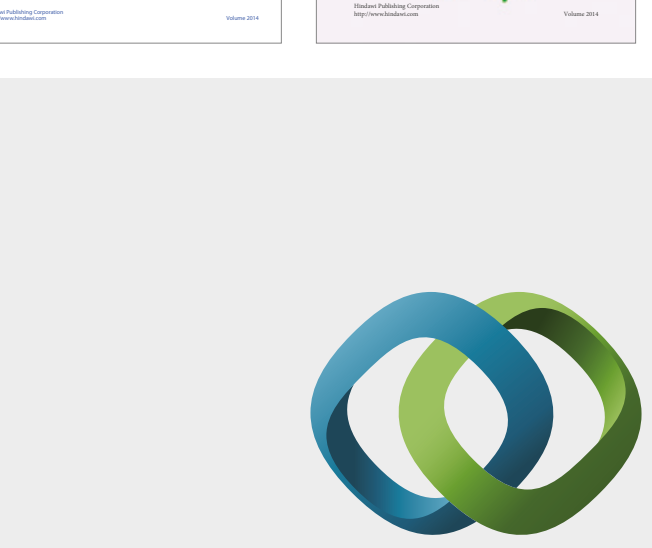

\section{Hindawi}

Submit your manuscripts at

https://www.hindawi.com
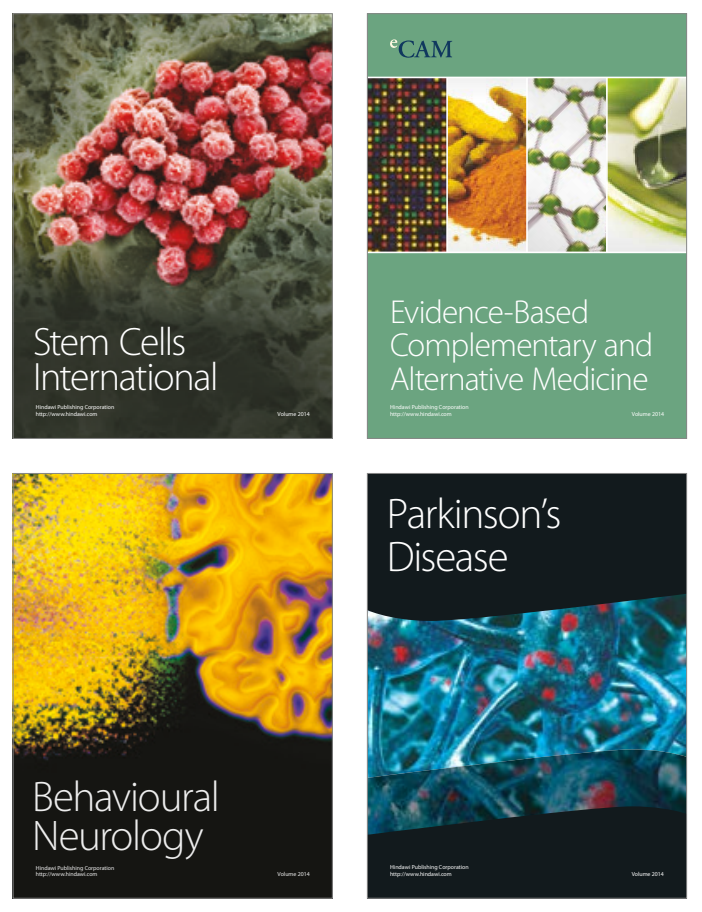
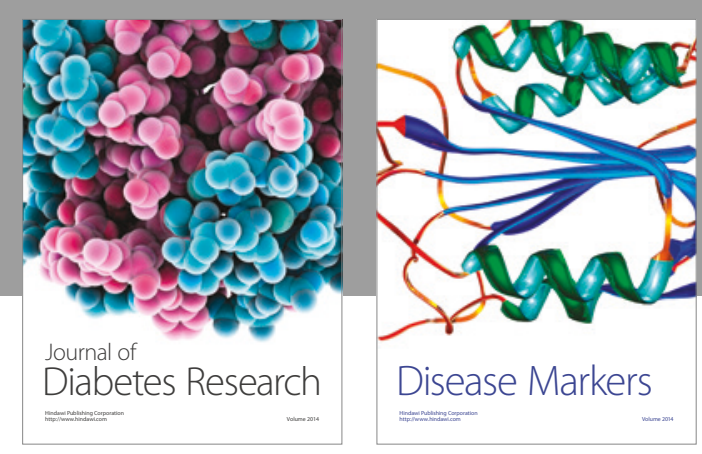

Disease Markers
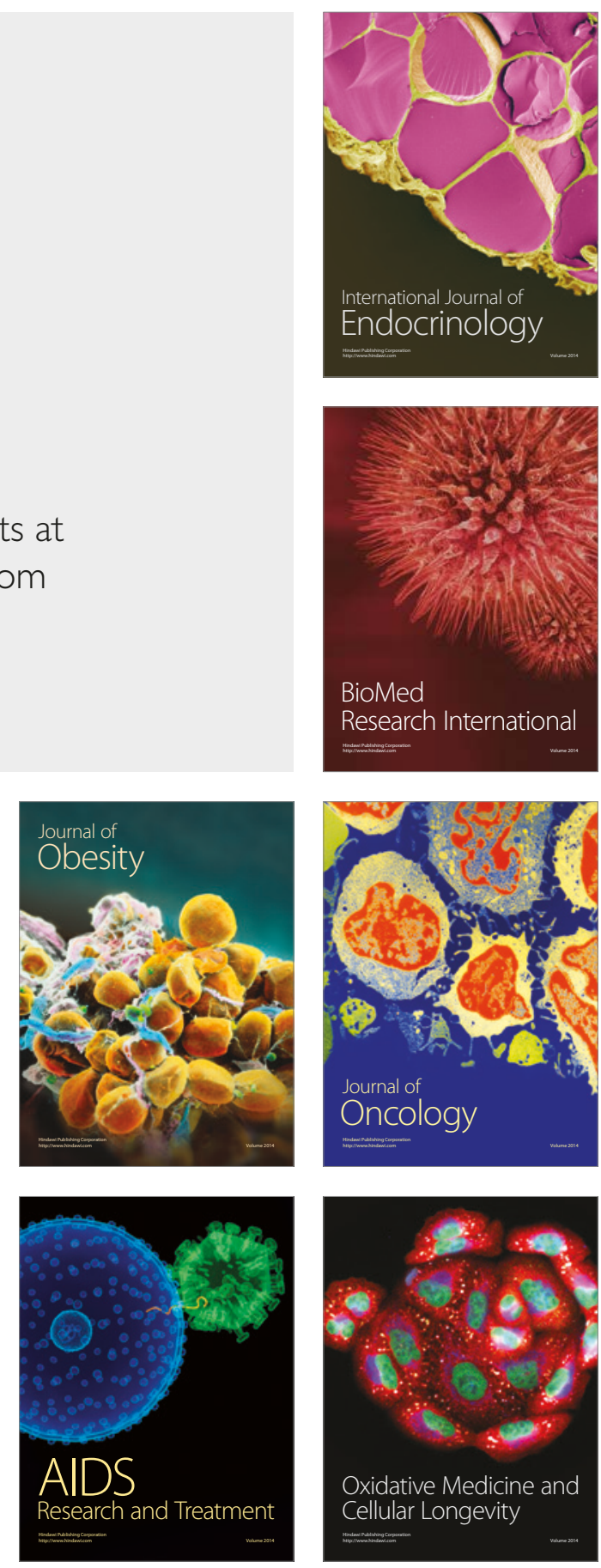